This item was submitted to Loughborough's Research Repository by the author.

Items in Figshare are protected by copyright, with all rights reserved, unless otherwise indicated.

Address terms in turn beginnings: managing disalignment and disaffiliation in telephone counseling

PLEASE CITE THE PUBLISHED VERSION

http://dx.doi.org/10.1080/08351813.2011.619311

PUBLISHER

(C) Taylor \& Francis (Routledge)

VERSION

AM (Accepted Manuscript)

LICENCE

CC BY-NC-ND 4.0

REPOSITORY RECORD

Butler, Carly W., Susan Danby, and Michael Emmison. 2019. "Address Terms in Turn Beginnings: Managing Disalignment and Disaffiliation in Telephone Counseling”. figshare. https://hdl.handle.net/2134/13331. 
This item was submitted to Loughborough's Institutional Repository (https://dspace.lboro.ac.uk/) by the author and is made available under the following Creative Commons Licence conditions.

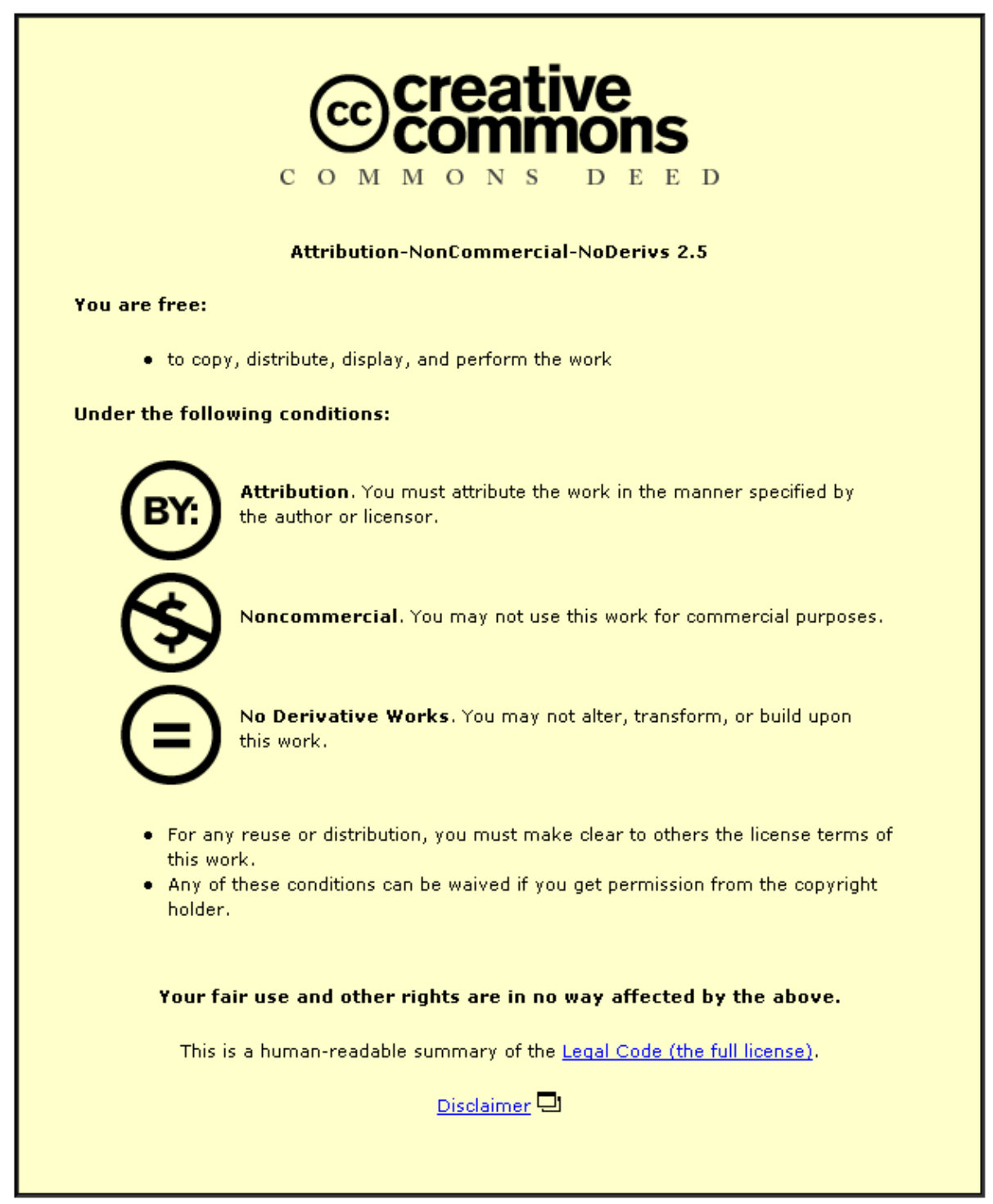

For the full text of this licence, please go to: http://creativecommons.org/licenses/by-nc-nd/2.5/ 
Address terms in turn beginnings: Managing disalignment and disaffiliation in telephone counselling.

\section{Carly W. Butler, Susan Danby, Michael Emmison}

\section{Acknowledgements:}

We thank Kids Helpline and BoysTown, and the counsellors and clients who took part in this study. This paper has benefitted from the comments of members of the Transcript Analysis Group in Brisbane and the Discourse and Rhetoric Group at Loughborough University. We are particularly grateful to two anonymous reviewers for their helpful feedback on earlier versions of the paper. This project was funded by an Australian Research Council Discovery grant (Project ID: DP0773185). 


\title{
Address terms in turn beginnings: Managing disalignment and disaffiliation in telephone counselling
}

\begin{abstract}
This paper examines use of address terms by counsellors on a telephone counselling service for children and young people. Drawing on conversation analytic findings and methods, we show how personal names are used in the management of structural and interpersonal aspects of counselling interaction. Focusing on address terms in turn-beginnings - where a name is used as, or as part of, a preface - the analysis shows that address terms are used in turns that are not fitted with prior talk in terms of either the activity or affective stance of the client. We discuss two environments in which this practice is observed: in beginning turns that initiate a new action sequence, and in turns that challenge the client's position. Our focus is on the use of client names in the context of producing disaligning or disaffiliative actions. In disaligned actions, counsellors produced sequentially disjunctive turns that regularly involved a return to a counselling agenda. In disaffiliative actions counsellors presented a stance that did not fit with the affective stance of the client in the prior turn, for instance, in disagreeing with or complimenting the client.

The paper discusses how such turns invoke a counselling agenda and how name use is used in the management of rapport and trust in counselling interaction.
\end{abstract}




\section{Introduction}

One of Harvey Sacks' earliest lectures discussed how telephone counsellors offered their name when answering the phone in order to encourage the client to then proffer their own name. Sacks' primary concern was with how the sequential organisation of greeting sequences afforded this exchange, and made avoiding giving one's name potentially problematic for the client. Watson (1981) pursued investigation of address terms in counselling and, like Sacks, his key interest lay in the intersection between organisational practice (i.e. obtaining client's names) and the interactional means of achieving this. Watson discussed the institutional 'need' to obtain client's names, but the matter of what sort of counselling and interactional work was accomplished by the use of address terms was not considered in any detail. This study builds on the work of Sacks and Watson by examining the use of address terms within the actual work of counselling.

In multi-party conversation, address terms can be used to establish the directionality of talk and select next speaker (Clayman, 2010; Sacks, Schegloff \& Jefferson, 1977). However, in two-party interactions, such as a telephone counselling session, there is no need to disambiguate the intended addressee so address terms, and the reasons for using them, are thus in many respects redundant (Clayman, 2010). Nevertheless, people regularly use the name of the person they are speaking to in two-party ordinary conversations (Jefferson, 1973; McCarthy \& O'Keeffe, 2003) and institutional interactions (Rendle-Short, 2007; Clayman, 2010 ) which has led researchers to examine why address terms are used in these two-party interactions.

There are two recurring themes within research on address terms. The first is that address terms are 'loci for formulating, maintaining and reformulating the status of a relationship' (Jefferson, 1973, p48). This function of address terms is described in terms of managing face concerns (Brown and Levinson, 1987), levels of intimacy (Brown and Ford, 1961; McCarthy and O'Keefe, 2003) and stance (Lerner, 2003). The second theme is that address terms are used in the context of managing the structural organisation of interactions - that is, in managing turn and topic transitions (Lerner, 2003; McCarthy and O'Keefe, 2003; Rendle-Short, 2007; Wootton, 1981). For example, in a study of children's pretend play, Emihovich (1981) found that children regularly used each other's 'real' names at various boundaries and transitions with the play episode, that is, in shifting from one type 
of play activity to another. Personal names were thus used in the organisation of chunks of talk and action within an interaction. In a corpus-based study of name use in radio talk and everyday conversations, McCarthy and O'Keefe (2003) found that address terms were used in relation to 'topic and turn management, face concerns, general relational concerns, humour/badinage and summons' (pg 153), offering quantified support for the centrality of sequential and interpersonal functions of address terms.

Within interactional research, it has been suggested that address terms in two-party conversation (as well as in multi-party talk where recipiency is not ambiguous) are used to demonstrate a particular stance towards the recipient. Lerner (2003) suggests this is particularly the case in post-positioned address terms which can be used to 'demonstrate a particular stance toward or relationship with a recipient under circumstances where that demonstration is particularly relevant' (p. 185). In the examples presented by Lerner, stance involves a display of personal concern for the addressed party. In a study of the use of 'mate' in everyday and radio interaction, Rendle-Short (2010) suggested that the positioning of this address term is related to the interactional context and could be used flexibly to manage the social distance between interlocutors.

Some of the most detailed conversation analytic accounts of personal name use in interaction come from studies of address terms in news interviews, and have described how names relate to both sequence and stance. Rendle-Short (2007) focused on the positioning of address terms within political interviews, and notes that journalists tend to use names in pre-position (at the beginning of turns) as a means of managing the organisation of the interview. For instance, journalists used address terms when initiating a new topic, or in initiating a move to a closing sequence. Address terms are described as shift-implicative and can serve as a kind of 'warning' to the recipient that what will follow is of some importance. Rendle-Short also discussed relational uses of address terms and in particular how address terms were used in adversarial environments and the delivery of disagreements and dispreferred responses. These relational aspects of address terms intersect with structural management in the case of overlap within disputes, for instance, politicians used address terms while the interviewer was still speaking as a bid for speakership and to position the other person as recipient. 
Clayman's (2010) analysis of broadcast news interviews focused on two 'responsive action environments' (p. 3) in which address terms were used - disalignment and expressive actions. Disaligning actions included disagreements and departures from topical and action agendas ${ }^{1}$. Address terms tended to appear at or near the beginning of the turn when used in relation to these actions, and it is argued that the name use delays the start of the disaligning response by breaking contiguity between the IRs question and the disaligning response. Clayman suggests that the 'attention-getting property' of address terms marks a turn as 'less than fully responsive' to the prior by producing the response as somewhat independent of the question. In this sense the address term is used to design a turn as a potentially "first" action.

Address terms are also used in cases of what Clayman (2010) describes as speakers doing 'speaking from the heart' ( $p$ 18). These instances include those where speakers work to display the sincerity of what they are saying (in relation to a belief, thought, desire and so on), and particularly in inhospitable environments - where there has been an overt or implied doubt about the interviewee's position. These 'expressive actions' are those that are 'attuned primarily with the speaker's own talk' (Clayman, 2010, p. 11) rather than the talk that has come prior, and in this way address terms are argued to be used in turns designed to stand out from the background talk. This work of foregrounding the turn can serve to intensify the significance and seriousness of what is being said now in comparison to what was said before.

In Clayman's (2010) study, the focus was on the use of address terms in turns responsive to a prior turn. Similarly, many of Rendle-Short's (2007) examples involve address terms in second position the exceptions being cases where journalists use pre-positioned address terms in turns initiating a topic change. The positioning of an address term within a turn in which it is used, within the immediately local sequence in which it occurs, and the positioning of that turn and sequence within the broader extended sequence, may be systematically related to the actions being done in with these turns. Furthermore, past research has shown how relational and sequential matters in the use of address terms are inextricably related. For instance, when journalists use the politician's name in turn-initial position, they not merely manage topic transition, but invoke and make relevant the

\footnotetext{
${ }^{1}$ Clayman (2010) uses a broad sense of disalignment to include actions like disagreement. As described below, in this paper, we draw on Stivers' (2008) distinction between alignment and affiliation to refer to the ways in which actions depart from a prior speakers' stance or from the activity in progress, respectively.
} 
identities of the participants as journalists and interviewee. As Clayman suggests, there are benefits in putting aside the question of what address terms ' $d o$ ' and instead focusing on the environments in which they occur.

This paper extends past conversation analytic research on sequence, social action, and interpersonal matters in environments where address terms are used. Specifically, it examines how name use is used in the management of sequence organisation and stance. The findings contribute to understandings about address term use as a core interactional practice that may be context-free and relate to name use in a range of settings. By applying these findings to counselling interaction, we shed new light on the interactional bases and regularities of this institutional practice and how client/counsellor identities are made relevant, and explore the therapeutic implications of counsellors' use of client names.

Whereas new interviews are contexts where we might expect challenges and disagreements between participants, in counselling interactions counsellors are expected to establish trust and rapport with the client. Taking a stance that is opposed to that of the client, then, is expectedly done in a way that maintains a sense of trust and rapport between parties. Handbooks and guidance on counselling skills identify the use of names as a key method for establishing rapport with a client, suggesting counsellors use the client's name periodically throughout a counselling session (Ivey, Ivey \& Zalaquett, 2009). Using names is described as a means of displaying a total focus on the client as part of a person-centred approach. Ivey et al (2009) suggest that names are an effective means of softening and personalising recurrently used 'sentence stems' that can otherwise sound formulaic, such as the prefaces typically used before paraphrasing what a client has said: for example, 'Sarah, it sounds to me like ...' While name use as a strategy has been discussed in relation to counselling techniques, we are not aware of any empirical examination of counsellors using client names in actual counselling interactions. Conversation analysis provides a means of exploring how intuitive understandings about using a client's name relate to the pragmatic and situated use of names within the moment-by-moment organisation of counselling interactions. This paper thus contributes to a growing body of conversation analytic work that examines how conversational and therapeutic practices and actions are used and organised in psychotherapy and counselling (e.g. Danby, Butler \& Emmison, 2009; Hutchby 2007; Perakyla et al., 2008). 
Our analysis focuses on the use of address terms in turn-beginnings. This includes names in turninitial positions (e.g. 'Esme you're doing an amazing job', see extract 5), names used as a standalone preliminary action such as a summons (e.g. 'Salma?' followed by a gap and then a go-ahead from the client, see extract 6), and names that are within a preface to a turn (e.g. 'So Adam, just outta curiosity ...' see extract 2). Initial analysis of name use in a variety of positions suggested that address terms in turn-beginnings were found in distinctive interactional environments; supporting past conversation analytic literature on a relationship between positioning of an address term and the social action being done in the turn a name was used. ${ }^{2}$ The positioning of a client's name at the beginning of a turn is identified by Ivey et al. (2009) as useful in personalising and softening what they describe as 'sentence stems' preceding what conversation analytic literature refer to as formulations (e.g. Antaki, 2008). ${ }^{3}$ However, we noted that one context in which counsellors used names in turn-beginnings was prior to some sort of disagreement, contradiction, or challenge to what the client had been saying in the preceding turn. Moreover, such turns seemed to be - in a lay sense - interruptively positioned; they occurred where a client was still speaking, or where some other turn or action might be expected by the counsellor. Our interest in these specific relations between turn design, sequential organisation and social action led to our focus on how address terms crop up in environments where there is some sort of disjunction, and where issues of alignment and affiliation appear to be interactionally relevant. The analysis therefore focuses on the use of address terms in turn-beginnings that occur in talk that is disjunctive from the surrounding talk in both structural and interpersonal aspects.

We draw on Stivers' (2008) discussion of alignment and affiliation in story-telling to examine how turns in which address terms are used as part of a preface relate to the wider sequences in which they occur. By alignment or disalignment we refer to how well an action fits with the activity in progress

\footnotetext{
${ }^{2}$ While we have observed that address terms in turn beginnings are used in distinctive environments that are detailed in this paper, future research will examine in more detail the patterns between positioning of an address term and the interactional environments in which they occur. Preliminary observations suggest some regularities between address term positioning and social actions - for example, two common environments in which turn-final address terms are used are a) where a counsellor asks for additional information or clarification of something the client has said, within an ongoing sequence, and b) at the end of a compliment to the caller. As discussed in this paper, we also find that address terms are used to preface a compliment. Initial analysis suggests that compliments with post-positioned names tend to come at the end of a sequence where a counsellor might be expected to provide some sort of assessment of the client's prior turn. On the other hand - and as we illustrate in this paper - compliments with address terms in turn beginnings seem to be delivered in slots where the compliment is sequentially disjunct (or, disaligned, Stivers, 2008).

${ }^{3}$ Interestingly, we observed few instances of address terms preceding such formulations - indeed, where client names were used in formulations, they tended to be in a turn-medial position, i.e. after a sentence stem and prior to a formulation (e.g. 'It sounds to me, Sarah, that ...').
} 
(i.e. its structural fittedness); whereas affiliation refers to how a counsellor's turn relates to the affective stance displayed by the client in prior talk (i.e. its interpersonal fittedness) (Stivers, 2008). We suggest that the management of alignment and affiliation are interrelated in the cases we describe, which illustrates how relational issues are managed in the structural organisation of interaction. Affiliation involves attending to the affective stance of the client thus address terms can be seen on one level to contribute to the interpersonal relationship between counsellor and client. In addition to this, we argue that the institutional identities of client and counsellor are invoked through the specific practices with which stance is managed, and through more general practices relating to issues of asymmetry in institutional interaction. The detailed empirical examination of address terms thus aims to reveal how social structures and practices are produced and managed in the moment-by-moment organisation of telephone counselling interactions.

\section{Data}

The data are from a collection of fifty telephone calls to Kids Helpline, a nationwide Australian 24hour free counselling service for children and young people up to the age of 25 . All counselors are paid and tertiary educated, and take part in ongoing accredited training at Kids Helpline. The two guiding beliefs and values shaping Kids Helpline practice are empowerment and child-centered practice (see Butler et al., 2010). A selection of calls was recorded as part of a larger project on the impact of technological modality on counselling interactions (e.g. Danby, Butler \& Emmison, 2009). All callers heard a wait message advising that the call may be recorded, and participating counsellors asked their clients at the end of the call if they gave their consent for the call to be used for university research. All data were anonymized onsite, involving the deletion or masking of any identifying information including name use. Pseudonyms were allocated that matched the original name in terms of syllables, consonant and vowel distribution, ethnic origin, and ability to be shortened if both forms were used in the course of a call (e.g. Jen and Jennifer). Prior to the deletion of the name, environments in which names were used were transcribed using detailed Jeffersonian conventions (Jefferson, 2004) that accurately captured the timing of silence around the name, the positioning of overlap, intonation, sound stretches and stress features.

Unlike some telephone counselling sessions examined by Sacks (1995) and Watson (1981), Kids Helpline counsellors do not give their name to the clients when they answer the phone, and neither 
do they seek the client's name in the opening of the call. This is to preserve the anonymity of the caller and to avoid putting the onus on the caller to reciprocate by offering their name. Instead, they answer with a greeting and institutional identification such as "Hi, Kids Helpline" (see Danby, Baker \& Emmison, 2005). If the client's name is sought by the counsellor, this tends to occur later in the call - for instance after the counsellor has receipted the client's 'problem presentation' and reason for the call and prior to further questioning, or not until the end of the call in some instances. Upon the client giving their name, counsellor's regularly then give their name. One main purpose for the sharing of names is so that the counsellor can start a file on the client to assist if they contact the service on another instance. The client can reconnect with the same counsellor and request for that counsellor on any subsequent contact with the service. In total, names were provided by the client in $85 \%$ of calls ${ }^{4}$.

\section{Analysis}

The analysis focuses on two specific contexts associated with the use of the client's name in a turnbeginning, both of which involve a disjunction between the preceding talk and the talk following the use of the address term. The first of these, which make up the majority of cases, involves turns initiating new action sequences after a prior sequence has come to a close. The second involves turns that are disjuncted in the sense that they are non-aligned in that they do not fit with the activity in progress and non-affiliative in that they involve the counsellor taking a different stance from that of the client (c.f. Stivers, 2008). Together, these contexts account for all uses of address terms in turn-beginnings found in the collection, suggesting that there is a distinctive relationship between the practice and actions being done with that practice. It should be noted that the majority of cases are found in initiating a closing sequence, however, our primary interest is in turns that come in the main section of the counselling interaction.

\section{Address terms in disjunctions: initiating new action sequences}

\footnotetext{
${ }^{4}$ Personal names are also used in email and online counselling and there appear to be some similarities in the interactional use of names across the different counselling modalities (see Harris et al, under review).
} 
We begin with some cases of address terms used in turns that initiate new action sequences. In these examples, address terms occur in environments of action or topic transition and mark subsequent talk as disjuncted from the prior sequence.

In the first example, the client had called about a boy (Linton) who was being disruptive and annoying within the classroom.

\section{Extract 1}

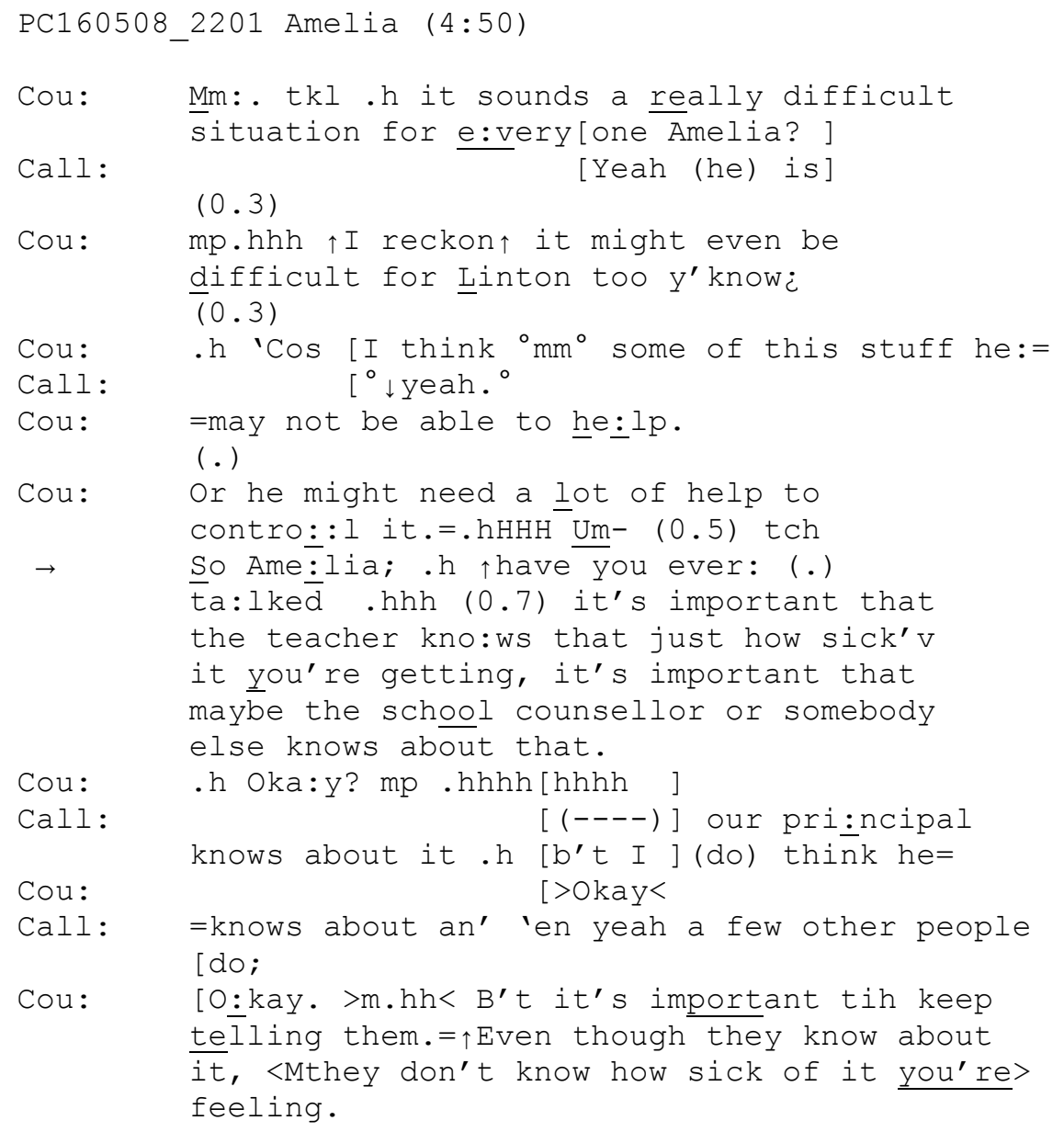

In lines 1 through to 13, the counsellor receipts the client's account of Linton's behaviour and his impact on the classroom environment through a summative formulation (lines 2-3), and account of how Linton himself may experience his behaviour. ${ }^{5}$ At line 13 the counsellor brings her turn to a point of possible completion, but rushes straight into an in-breath and an emphatic 'um,' which

\footnotetext{
${ }^{5}$ Note that an address term is used in line 2 in a turn-final position. As stated, our focus is exclusively on address terms in turn-beginnings so we have not discussed this name use here.
} 
signal a continuation and serve as turn-holding devices. The projected next turn is launched at line 14 with the pre-positioned 'So Amelia' and initiates a new action sequence involving a shift towards a 'problem management' sequence with allusions to a specific course of action the caller could take to deal with the situation (talking to a teacher or school counsellor) ${ }^{6}$. While the topic of 'Linton's behaviour' remains live, the address term is positioned at the boundary between two distinct sequences of action. The first was a responsive action to the client's problem presentation and the second is an initiating action relating to managing that problem. In this respect, there is a shift in the action agenda (Clayman, 2010).

The address term is pre-positioned relative to the turn unit in which it occurs, but is itself preceded by the token 'so'. Bolden (2006) has observed that 'so' prefaces are found in 'recipient-attentive' topic shifts. In this case the shift in agenda also entails a shift to the effect that Linton's behaviour has on the client, which contrasts with the earlier focus on how Linton's behaviour effected the class (see lines 1-2: 'a difficult situation for everyone'). In the the so+address term prefaced turn, the counsellor's stress on 'you' (in lines 17 and 28) clearly emphasizes the relevance, and importance, of the client's own situation. Bolden (2009) has also shown that 'so' is regularly used to indicate that the action being launched has 'emerged from incipiency' (p. 975). In characterizing an action as one that has been pending, speakers can use 'so' to present themselves as enacting their agenda. In the context of Kids Helpline calls, establishing a means of dealing with the client's problem is an agenda that remains incipient throughout the counselling interactions. In this example, the sequence shift managed by the counsellor attends to the ongoing incipiency of helping the client deal with her problem.

As well as being used in managing the shift to a new action (i.e. managing the structural organization of the interaction), there are specific interpersonal or relational aspects to the action done in the turn prefaced with the client's name. The work of the address term in managing a shift in action is inextricably linked to the management of the shift in the relational organization of the

\footnotetext{
${ }^{6}$ The counsellor begins with what we have elsewhere termed an 'advice implicative interrogative' (Butler, Potter, Danby, Emmison and Hepburn, 2010) - the use of an interrogative format to forward a suggestion for future action. In this case the interrogative takes the form of a history-taking question which can operate as a 'preliminary' to the delivery of a suggestion. However, the counsellor cuts-off and restarts the turn with an assertion about the 'importance' of talking to someone, although she does not invoke the caller's agency in carrying out this alluded to action. It is possible that the lack of agency attributions softens the prescriptiveness of the assertion, whilst maintaining the normativity of the alluded-to action.
} 
parties. An orientation to an incipient agenda involves, in this instance, a move towards 'counselling work' and makes salient the memberships of the participants as counsellor and client. The counsellor's assertions about what the client might do about the situation have an imperative tone to them ('it's important that ...' lines $15,17,26$ ), which displays and produces the asymmetry of the relationship at this point. These shifts in terms of the relations between client and counselors

A second example of these features of turn design and the sequential and interpersonal environment associated with name use is shown in extract 2. The client had earlier presented his reason for calling as having problems with anger management and friendships. Just prior to the extract shown, there had been an extended sequence of talk about the client's favorite television shows that had led on to discussion about a gardening project the client was doing with his parents (the 'hard work' mentioned in line 1 below).

\section{Extract 2}

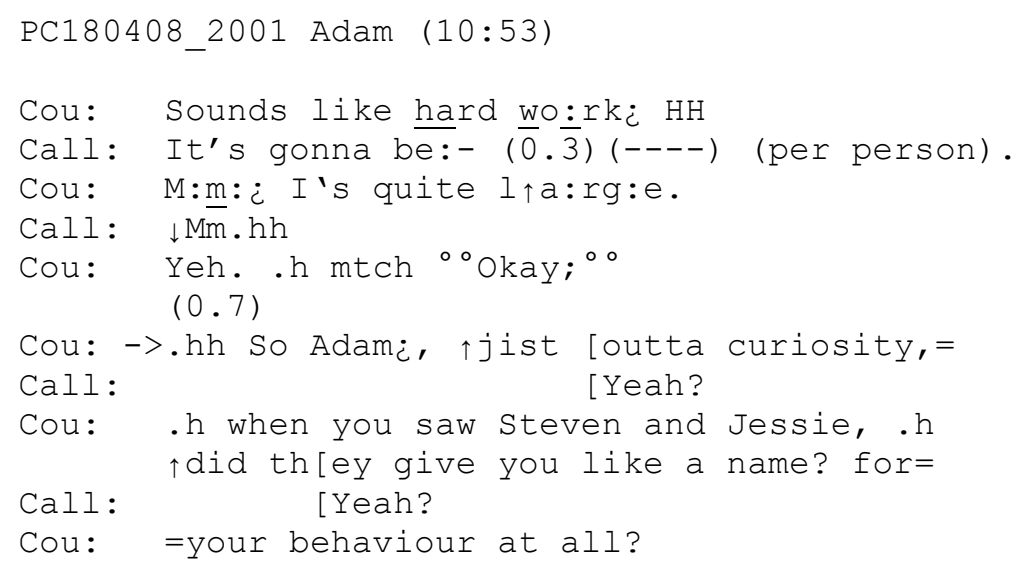

The counsellor's acknowledging receipt and quiet 'okay' at line 5 is implicative of a closing of the prior sequence (Beach, 1993). In the next turn, the counsellor's preface 'So Adam' signals the initiation of a new action sequence and marks a transition back to the 'business' of the call. While the client treats the address term as an attention-getting summons as demonstrated by the go-ahead 'yeah' (line 8), the absence of a slot for such a response, and the consequential overlap, shows the counsellor's use of the address term as a preface. The design and positioning of the turn thus is very similar to that noted in extract one, with similar interactional work accomplished. 
In this extract, there is a shift in both topic and action agenda with the counsellor's enquiry as to whether the professionals Adam had seen had given him a 'name' (i.e. a diagnosis) for his behaviour. There is a shift in topic from television and gardening to the client's behaviour and possible 'condition,' and a shift in action agenda in that the counsellor initiates a shift back into the role of 'questioner' about the client's issues, rather than recipient of 'news' or stories. ${ }^{7}$ In both respects, the shift entails a return to the incipient topic and action agenda, to the 'clinical' aspects of the interaction. While the client moved away from talking about the problem, the counsellor now returns the conversation to focusing on what (diagnostically) might be behind Adam's behaviour. There is the sense that this issue had been pending and remained relevant throughout the course of Adam's other talk, and as in extract one the prefacing 'so' appears to produce the turn as part of an incipient agenda, and as one that is other-attentive (Bolden, 2006, 2009).

While there is no doubt that 'counselling work' is accomplished by offering the client interactional space to talk about his hobbies and family, the tone is more conversational than explicitly therapeutically oriented. As with extract one, the structural shift also involves a shift in terms of how the participants are positioned relative to one another. The counsellor makes relevant and consequential her membership as a professional, and Adam's membership as a 'client' who has called specifically about the behavioural difficulties he is dealing with, as Adam had mentioned his anger management issues as a reason for calling in the initial part of the call. Furthermore there is a certain delicacy involved in returning to the operational relevance of these memberships and the topic of Adam's behaviour after the more innocuous topic of garden projects with the family. The counsellor's inserted 'jist outta curiosity' goes some way towards minimising the consequentiality of the question, and perhaps the clinical relevance of the enquiry.

In extracts one and two, then, address terms are used in environments where a turn is disjuncted from the immediately prior talk and involves a shift in the action and/or topic agenda. In conjunction with the use of 'so', the address terms mark this transition and signal a return to an incipient agenda (Bolden, 2009). In these respects, address terms are clearly used in the management of the structural organisation of the counselling interaction and in particular where there is a sequential lack of alignment. In addition, the subsequent actions also entail a shift in the positioning or stance of the

\footnotetext{
${ }^{7}$ The client's account of gardening was not directly prompted by questioning from the counsellor, but emerged from a discussion about favorite television shows.
} 
participants. First, the following actions are in both cases 'other-attentive' (Bolden, 2006), in that they involve a return to the relevance of the client as a 'person with a problem' which contrasts with prior talk as somewhat neutral in comparison, or involving attention towards third parties. Second, in both cases the So+address term formulation is used as a preface to a question. Questioning makes relevant a fitted answer by the client and thereby constrains the client into responding in terms of the counsellor's agenda (Heritage \& Raymond, forthcoming), making difficult any return to the preceding talk. A final, related, matter is that the shift into the incipient agenda is one in which the memberships of the participants of counsellor and client are relevant and consequential. By initiating talk about strategies for dealing with a problem, or about a clinical diagnosis, the counsellors make operational their role as professionals. They also invoke their right to control the overall direction and organisation of the talk, making the asymmetrical relationship between client and counsellor relevant. In this respect, the shift prefaced by the address term (and 'so') is sequential and also relational.

The turns prefaced with So+address term are disjunctive in that they mark both the closing of prior talk and initiation of a new sequence, and in this sense are not aligned with the preceding action or topic. Further, by shifting into a more clearly 'counselling agenda' the counsellor's turn can be seen to not affiliate with the stance of the client in the preceding talk. However, these are not disaligned or disaffiliative turns, in that they do not disrupt or challenge ongoing talk and displays of stance. Through their positioning in sequentially appropriate slots for a shift in action and stance, the turns could be described as normatively disjunctive - they occur at boundaries, and are a method for creating and making visible a boundary between one sequence and the next. Sequence initiation was the most common context in which address terms in turn beginnings were observed, and typically this was observed in opening up a closing (Schegloff \& Sacks 1973) to the call. In subsequent examples, address terms do not come at a boundary between action sequences or at a transition into a new topic. Instead, they come in the midst of a clearly ongoing sequence and/or turn at talk. Their positioning within a course of action with a clear forward and ongoing trajectory is at times explicitly oriented to by the counsellors through the use of phrases and words that characterise their turns as potentially disruptive. In these examples, address terms are seen to be used in the management of disaffiliative and disaligning actions.

\section{Address terms in the context of disaffiliation and disalignment}


Having shown how address terms are used in turns involving the in situ organisation of chunks of talk and action, we turn now to examine disruptions of a chunk of talk on both a sequential and interpersonal level. That is, in cases where address terms are used in the beginnings of turns that are not only disjunctive, but also disaffiliative and disaligning. A characteristic feature of the following uses of address terms is that they are positioned either in overlap or before the end of a possibly complete TCU.

In the following example, an address term is used in the context of overlapping talk. To gloss the preceding talk, the client, Chantelle, had been talking about a girl called Caroline who has been causing her problems, including threatening to 'bash' her sister, Mel.

\section{Extract 3}

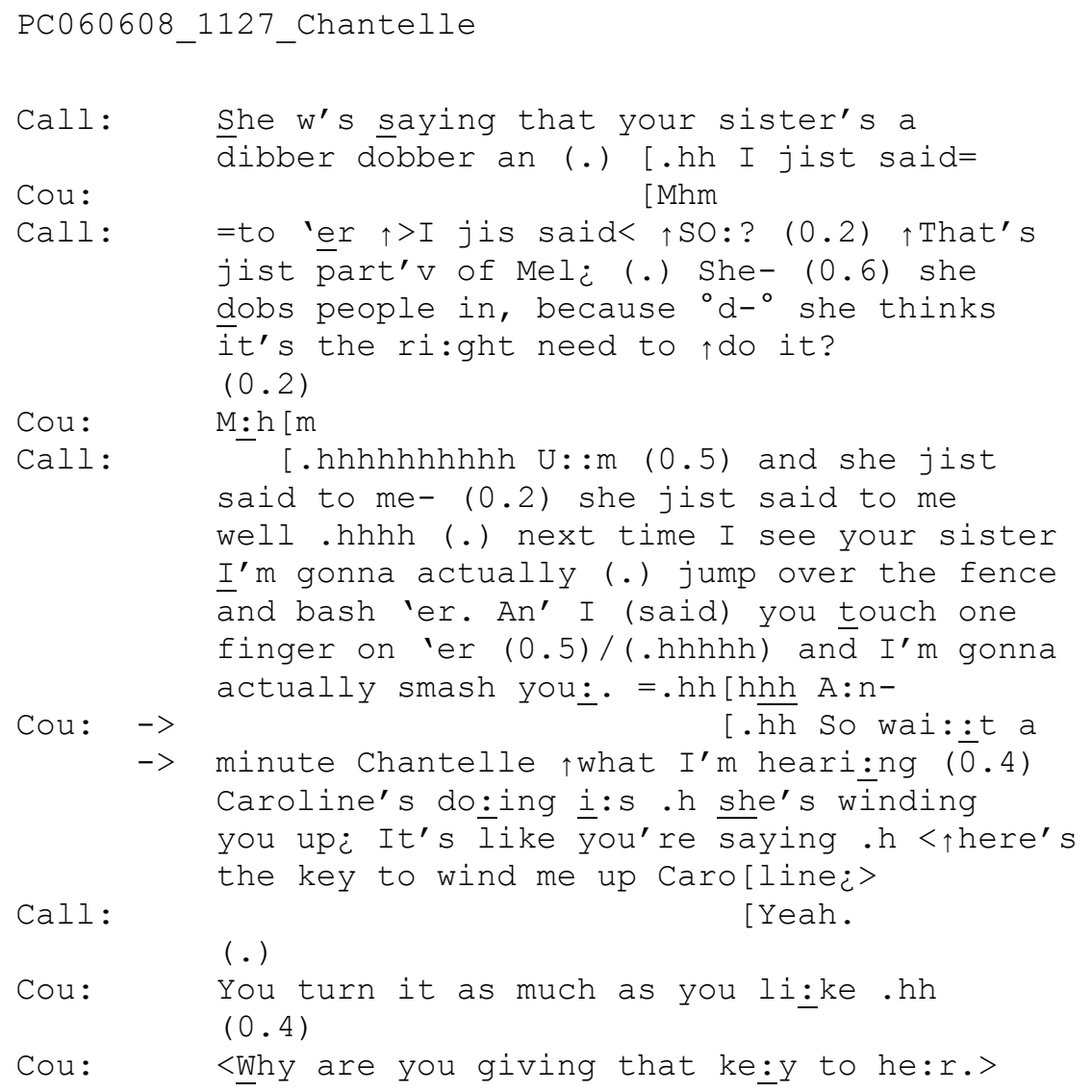

The client's account (and indeed large chunks of the call) involves a series of 'she said, I said' reports using direct reported speech (see Holt \& Clift, 2007) through which the caller describes 
her troubles with Caroline. Over the course of this account, the counsellor orients to the caller's turn as still in progress with the 'mhms' at lines 3 and 9 operating as continuers (Danby, Butler \& Emmison 2009; Gardner 2001). At lines 14-16, the client reports her response to a threat by Caroline had been the issuing of a retaliatory threat to 'smash' Caroline if she 'touch(ed) one finger on' her sister. There is a point of possible completion at line 16, both pragmatically and in terms of the use of turn-final intonation, which could make for a transition relevant space, but the client latches an in-breath and the conjunction 'an(d),' which projects more to follow (line 17) and cancels the transition relevance of her completion. However, after the initiation of the continuing in-breath, the counsellor also takes an in-breath to signal that she is starting up. With 'so wait a minute Chantelle,' the counsellor produces her turn as one that is interruptive of the client's projected continuation and secures her own turn on the floor. The client's name is postpositioned in relation to the turn constructional unit in which is it used - the directive to 'wait', The turn then is extended with a reformulation of the client's account, or, reinterpretative statement (Bercelli, Rossano \& Viaro, 2008), and then an enquiry about that reformulation (lines $18-21 / 24)$.

Through the directive to 'wait a minute', the counsellor does an explicit interruption, which demonstrates an orientation to the client's turn as still in progress and asks for this to be held back. The counsellor's turn is disaligned with respect to the activity in progress in that it disrupts the progressivity of the client's talk and undermines the structural asymmetry of the tellerrecipient positions (Stivers, 2008). The counsellor does not wait for a clear transition relevant space and takes the conversational floor by initiating a pre-emptive shift from recipient to speaker. The address term thus is used within the context of securing a turn at talk in a structurally disaligned position.

In the continuation of her turn, the counsellor offers a reinterpretation (Bercelli et al 2008) of the client's account of the series of events, to suggest that Caroline is winding the client up and that the caller is enabling this through her actions in response to Caroline. The counsellor emphasises the client's agency in enabling Caroline's actions through the hypothetical reported speech (lines 20-21, see Fasulo 1997), which is met with agreement from the client (line 22). The client is then asked to account for why she is giving the metaphorical key to Caroline. In this respect, there is 
quite a clear shift in the trajectory of action - it would be difficult for the client to return to the account she was in the midst of delivering prior to the counsellor's bid for the floor. While the counsellor's turn is in second position in the sense that it is responsive to the client's account (at least in terms of formulating what the client had been saying), it is also an initiating move that reverses the speaker's sequential positions and shifts the action agenda. This supports Clayman's (2010) observations about the use of address terms in responses that are 'less than fully responsive, built to be in varying degrees independent of what was projected by the previous turn' ( $\mathrm{p}$ 12). But, unlike extracts one and two, the initiated sequence is still bound to the prior turn.

Extract three has similarities with extracts one and two with respect to the use of an address term in a turn that manages the sequential organisation of the activity but is not structurally aligned with the immediately prior talk. There are also similarities in terms of the way the turn invokes and makes relevant the relational alignment of client and counsellor. The counsellor does archetypal counselling work through the reformulation and invitation for the client to engage with this reinterpretation of her actions (Antaki, 2008). The structural disalignment, then, offers a means for the counsellor to get out of the recipient role, and make operational her role as counsellor through the more therapeutically aligned action.

In addition to the broad organisational memberships in play, the shift in terms of sequence and action also implicates a shift in the immediately local socio-relational organisation. The client has presented a strong affective display in her telling, involving a potentially troublesome reporting of a threat to engage in retaliatory violence. Through her reformulation the counsellor presents a stance that differs from that of the client, proposing an alternative way of understanding the situation. The counsellor's emphasis on this formulation being her interpretation and independent from that of the client's (i.e. 'what I'm hearing', line 18), contributes to this being hearable as a reinterpretation (Bercelli et al., 2008, pg 48). In so doing she takes up a position that does not affiliate with the stance of the client. While there is no disagreement per se (cf Clayman, 2010; Rendle-Short 2007), there is no display of affiliation with the client's position, and with the action accomplished through the presented stance (possibly complaining about a third party). As we discuss in more detail later, the lack of 
affiliation may be integrally related to the work of the counsellor - and it may be not incidental that a personal name is used in the context of doing this sort of positioning work.

While the address term itself is just one of a range of interactional features noted in extract three, the analysis demonstrates a key aspect of the kind of interactional environments in which address terms are used in Kids Helpline interactions - where there are disjunctions in terms of sequence, and/or in terms of stance. Clients' names are regularly found where counsellors are managing displays of alignment and affiliation - alignment with respect to the activity, and affiliation with respect to the caller's stance, or 'affective treatment of the events' they describe (Stivers 2008, p. 37). In some cases the lack of affiliation with a client's stance is produced in the context of doing disagreement with a client, which can be a sensitive issue in terms of the management of client-counsellor relations. In the following examples we examine how address terms are used in turns that are more clearly disputative.

Extract 4 comes from later in the call from which extract 3 is taken, where Chantelle claims she could contact the education department to complain about unfair treatment from the school principal:

\section{Extract 4}

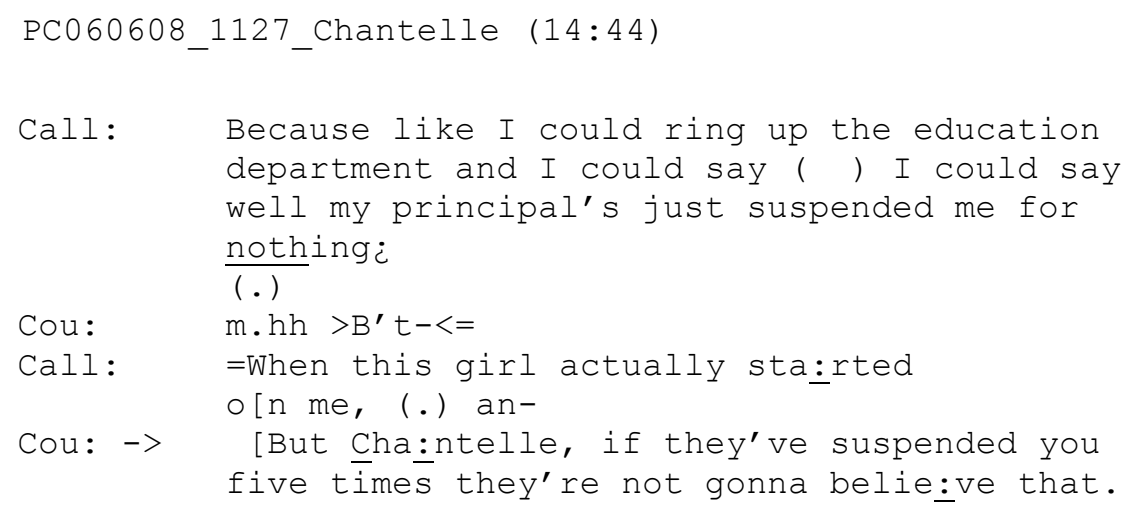

The counsellor projects a disagreement at line 6 with a compressed and cut-off 'but', but Chantelle extends her turn at lines 7-8. The counsellor restarts her turn in overlap, prefacing her challenge to the client's alleged course of action with 'But Chantelle' (line 9), which enables the substance of the turn to be said in the clear. Rendle-Short (2007) suggests that address terms in this context can be used as a 
device for dealing with overlap or, in lay terms, as a means of doing an 'interruption' by '”forcing" the other person into recipiency' (pg 1513).

The counsellor clearly takes an opposing position to the one of the client, through a disagreement with the plausibility of the client's proposed course of action. In this way, the counsellor provides an alternative assessment of the value of reporting to the education department. Antaki (2008) describes this practice, in which a 'therapist more or less explicitly contradicts the client and claims to reveal a truer state of affairs' ( $\mathrm{p} 27$ ), as a challenge or correction. The counsellor's challenge to the caller's stance that reporting the principal would bring justice is not affiliative. By virtue of the overlap with the client's still-in-progress turn, the turn is also structurally non-aligned, although aligned with the activity of describing/assessing future courses of action. In this example, lack of alignment and lack of affiliation are integrally related.

As noted above, a lack of affiliation with the affective stance of the client does not necessarily equate to the doing of what might be considered negative actions, such as criticism or condemnation. In the following example, the counsellor does not display affiliation with the stance of the client, but does a non-affiliative action to instead compliment the client. The 24 year old caller, an on-going client, has three children and also cares for her 16 year old sister. She had reported an incident where her sister had told her she was going to Megaland (a shopping mall), but had actually gone into the town/city. In lines 1 to 7 , the client tells what she had said to her sister, as part of a longer complaint about the sister's lying and the client's concerns for her safety.

\section{Extract 5}

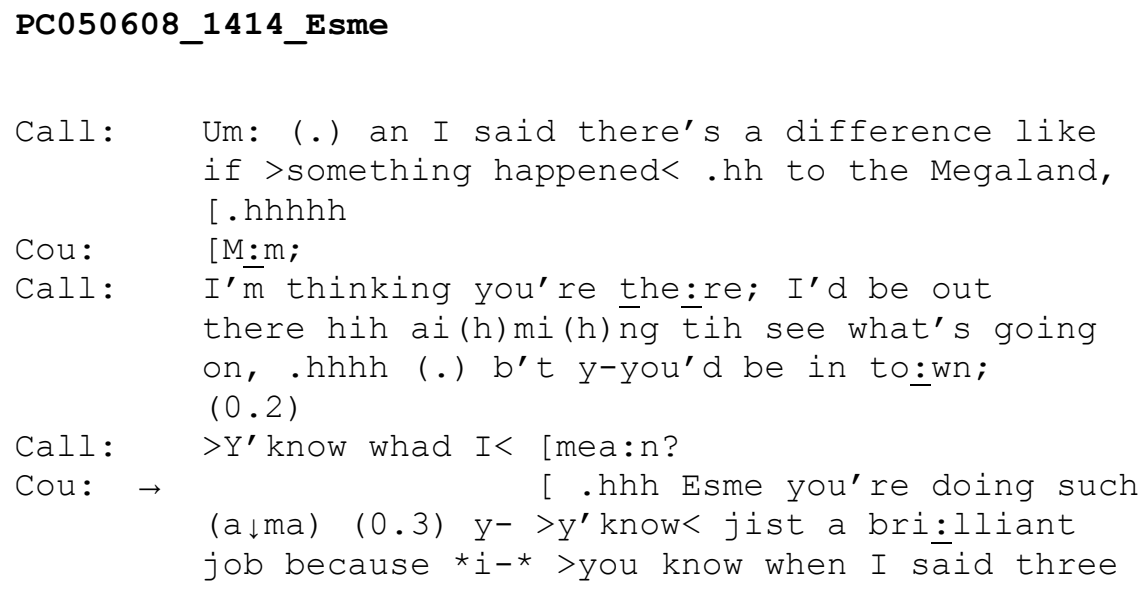




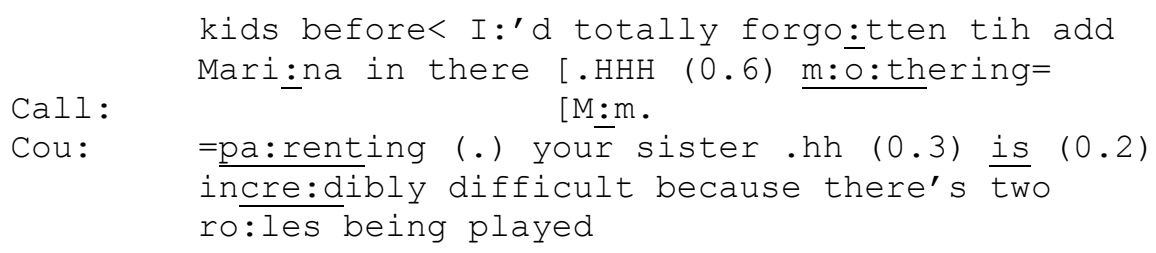

The client solicits a response and display of understanding from the counsellor at line 9, with 'y'know whad I mean?' The counsellor's response has a turn initial address term and goes on to compliment the client on the 'brilliant job' she does parenting her sister as well as three kids. The counsellor offers a positive evaluation of the caller, but this turn does not affiliate with the client's affective displays in the sense that it does not support or endorse the caller's displays of concern or annoyance. The turn is also disaligned in that it does not involve a response paired to the prior action of complaint or the display of understanding invited by the client, and thereby does not align with the activity in progress. It is sequentially out of place, displayed in terms of a disjunction of both topic and action ${ }^{8}$. The shift involves not talking about the client's sister's behaviour and/or safety, and not displaying understanding of the caller's account of the event. Instead, the counsellor makes an assessment of the client and her situation, an action that is arguably core to the counsellor's work as counsellor. As such, then, we again see the use of an address term in the context of the counsellor 'doing counselling'.

Extract 5 is the first example presented so far in which the address term is used without a preface we had 'so' in extracts 1 and 2, 'so wait a minute ' in extract 3, and 'but' in extract 4 . The turn itself in extract 5 also shows little direct tying to the surrounding talk with the exception of the reference to a much earlier reference to the client having three children. As both Rendle-Short (2010) and Clayman (2010) suggest, pre-positioned address terms can be used to give a turn status as a 'first' action, and alter the sequential ordering of the interaction. While we have observed this in other examples, this is perhaps the clearest case we have so far of the turn disrupting the sequential trajectory of the talk. Not only does the counsellor not deliver the invited second-pair part here (i.e. a display of understanding), she deletes the relevancy of the caller's just prior turn altogether. There is an appreciation of the difficulties facing the client as a parent in general, but no explicit orientation to the specific incident described by the client.

\footnotetext{
${ }^{8}$ The counsellor also uses this turn to correct an earlier error on her part in referring to Esme caring for three children. This tying to a previous section of talk (not in the immediately preceding sequence) also points to the 'out of placeness' of this turn in relation to the surrounding talk.
} 
The use of the address term as a preface appears to mark this turn as disconnected from the prior turn, and makes it stand out from the surrounding talk (Clayman, 2010). The turn itself is designed as one of some importance and supports Clayman's (2010) observation that address terms are used in news interviews where the speaker presents something as especially sincere, or, 'speaking from the heart'. The counsellor's compliment about the 'brilliant job' the client is doing and the extent of the 'difficulty' of this job are emphasised in this turn. The address terms appears to play no small role in highlighting the affective stance of the counsellor in her delivery. Yet it is not immediately clear what the address term itself is doing, in terms of social action. There is no need to say who the turn is addressed to and, while there is a very slight overlap, there is no need for the counsellor to signal that she is about to take a turn as she has been quite explicitly selected by the client as next speaker. Given that the address term, across all examples and as observed in related studies, is used in turns that are in some way disjointed from surrounding talk, it makes sense in this case to see the address term operating as an 'attention solicit' (Wootton, 1981). That is, the address term is not used because there is any specific difficulty in securing attention (the matter of overlapping talk aside, attention may be assumed in this sort of focused two-party interaction), but as a way of emphasising the importance of the client's attention being secured for the delivery of a turn that is in some way significant. The attention solicit function of the address term is particularly evident in cases where names appear to be used as summons (see Schegloff, 1968), in the context of producing disaffiliative and disaligning actions.

We saw in extract two that the client treated the counsellor's use of his name as a summons, as indicated by his responding 'yeah'. In that example, this 'go-ahead' appeared to be a misunderstanding about the action of the name use, as the counsellor did not leave a slot for the caller to signal their attention. In the extract below, the use of a name to do a summons is less ambiguous as the counsellor uses the client's name with a questioning intonation and provides a slot for the client to indicate their preparedness as recipient. In the extract shown the talk is around the client's father and his tendency to be overly controlling and verbally abusive. In prior parts of the call the client had been providing accounts and justifications for his behaviour.

\section{Extract 6}

PC130408_2002_Salma [37:30] 


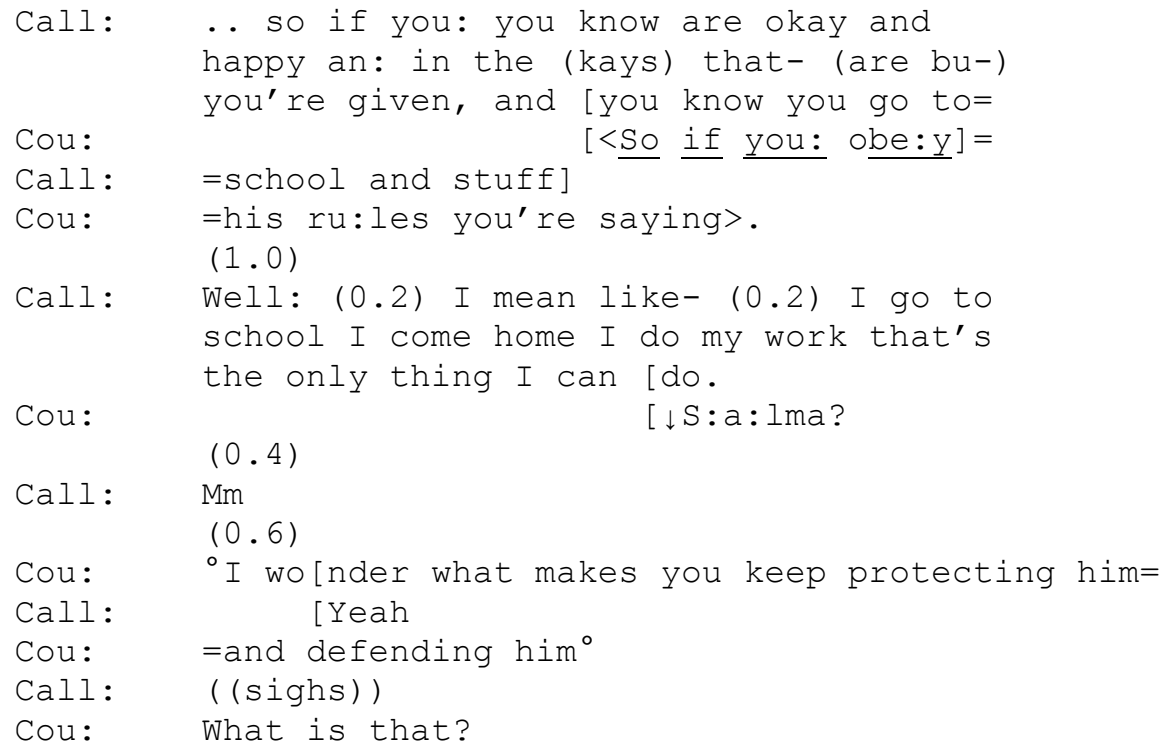


This example differs from the ones presented earlier in that the address term (line 11) is clearly delivered as an attention solicit due to the rising intonation and slot provided for a response to the summons ${ }^{9}$. Making sense of this turn requires looking back to the action being done by the counsellor's turn in overlap at lines $4 / 6$, where the counsellor offers a candidate understanding as a clarification request, beginning her turn in a non-transition relevant space. The client's response orients to the candidate understanding as in some way problematic, with the dispreferred marker 'well' (Schegloff \& Lerner, 2009) prefacing a weak disagreement. When the counsellor uses the address term the client has not quite completed her turn, but this is a reasonable enough position for a terminal transitional overlap as the name is begun just prior to the projectable end of a TCU (Jefferson, 1984). However, because the address term is not fitted to the prior talk, it seems disjunctive. It does not interrupt the talk in progress, but is disruptive of the sequence in progress and is, in this respect, disaligning with the prior talk. The counsellor does not directly acknowledge or receipt the client's account of her situation in a slot where this might be considered appropriate or even expected. Instead, she does a new first pair part that initiates a summoning pre-sequence.

The stand-alone address term, with questioning intonation, has the form of a summons and is followed by a silence that provides a slot for the client to acknowledge this summons. The address term therefore seeks and receives the attention of the client. By initiating the turn with a summonsresponse pre-sequence, the counsellor separates what follows from the prior talk. It secures the client's attention in the sense that it invites the client to align with the counsellor with respect to the projected next-action. In doing so, it projects what is to follow as being of some importance or significance (Clayman, 2010). In contrast to the other examples, the use of a summons makes explicit this work of getting the client's attention and alluding to the significance of what is to follow. A summons also has a stronger warrant as a form of 'interruption' in the sense of disrupting the action in progress. It emphasises the shift in sequence and action through the use of a summons as part of a pre-sequence. Thus, the turn for which attention is sought is separated from the past talk and action by the use of an address term as a turn beginning, and through the use of an address term to initiate a pre-sequence. In this way, the broken contiguity between the subsequent talk and that prior is more salient.

\footnotetext{
${ }^{9}$ For another example of an address term being used as a summons, see extract 4 in Emmison, Butler \& Danby (2010).
} 
In the subsequent turn (lines 15/17), the counsellor effectively reformulates what the client has said by characterising her description of her father's actions as 'protecting him and defending him'. The reformulation of the client's actions is disaffiliative in the sense that the counsellor is putting forward a different stance from the client, one that might be said to challenge the client's position. As with earlier examples, an address term has the effect of making a bit of talk 'stand out from the background of the turn in progress' (Clayman, 2010, p11), and the bit of talk that stands out is a reformulation. In these reformulations, counsellors engage in therapeutic interpretations of what the client has said, and foreground the work being done by use of the address term. The stance taken by the counsellors in these turns is one that highlights their capacity as a professional to make such reformulations.

\section{Discussion}

We have described some local interactional contexts in which address terms are used in turnbeginnings and outlined a situated account of address term use as a practice. The most intuitively appealing accounts as to why people use address terms in two-party interaction, such as a sociolinguistic account of address terms as a means of 'positive politeness' (Brown and Levinson, 1987) or of invoking closeness and social solidarity, are quite abstract. One advantage of the conversation analytic approach is that it reveals how fine-tuned the social and relational aspects of personal name use are, and how integrally they are tied to the sequential organisation of the interactional moments in which they occur.

The analysis has discussed instances where address terms are used in turns that are sequentially or interpersonally disjointed from prior talk and stance. Drawing on Stivers (2008), the turns in which address terms are used are regularly disaligning and/or disaffiliating with the activity or stance done in the previous turns. The analysis thus supports past investigations of address term usage that have shown that personal names are used in the context of managing the sequential organisation of talk, and is relevant for managing relational matters between people; in particular in the context of disagreement and disalignment, and in making a bit of talk stand out in some way from surrounding talk (Clayman, 2010; Rendle-Short, 2010). This paper offers new contributions in two main respects: First, it highlights and refines understandings about some of the fundamental and aspects of the structural and relational functions of address terms; second, the paper demonstrates how 
address terms perform context-specific functions in the unique interactional setting of telephone counselling.

Our focus in discussing the interactional organisation of the use of address terms has been on their work in the context of disjunctions of sequence and stance, which relate to Stivers' (2008) accounts of alignment and affiliation. In terms of sequential disjunction, we described how address terms were used in turns that initiated new action or topic agendas. In this respect, they were not aligned with the activity in progress in prior talk. In some cases (e.g. extracts 1 and 2), address terms were used in turns that were 'properly' first pair parts and initiating actions - coming after the closing of a prior sequence and clearly signalling the beginning of a new action sequence. In other examples, the disjunction was not as apparent, as names were used in a slot provided for a second pair part (eg. Extract 5), or in some cases, in a space that was not a slot or TRP at all (E.g. Extract 3) and could even be considered to be an interruption (e.g. extract 4). In these cases, the address term played an active role in marking the turn as not quite fitted to the prior and, as Clayman (2010) has described, as making a second a first. Address terms were thus used in reversing the order of speakership with the counsellor in some ways rejecting a position of recipiency, and inviting the client to do a specific second pair part, therefore highlighting their sequential position as recipient and next speaker. It is through this disjunction between the past and 'next' turn that the contexts in which address terms were used could be said to be disaligning. This does not imply a disagreement or 'clash', but simply that address terms are used where counsellors do not exactly take up or follow on from an 'activity in progress' - they start something new, or call a halt or pause to the activity done in the past turn.

The interpersonal aspects of address term use were observed in the ways by which turns involving a client's name could involve the presentation of a different stance from that of the client. Such turns were disaffiliated with the client's prior talk in terms of offering alternative understandings or positions through reformulations and reinterpretations (extracts 3 and 5) and disagreements (extract 4). These turns also involved actions that seem to highlight the relevance of the participants' memberships as 'counsellor' and 'client'. Examples one and two involved a return to the 'counselling agenda' and addressing matters core to the task of counselling - proposing future courses of action (Ex 1) and discussing diagnosis (Ex 2). Other examples involved offering formulations and reinterpretations, which serve as therapeutic tools (Antaki, 2008; Antaki, Barnes \& 
Leuder, 2005; Bercelli et al 2008; Vehvillainen, 2003). Our analysis thus addresses two key aspects of the interpersonal dimensions of name use. First, we see how relational work is observable in the turn-by-turn production and recognition of the stance of speaker and recipient, with address terms used as a means of marking subsequent talk as challenging the stance of the client in some way. Second, we observe that the institutionally shaped roles of counsellor and clients are made operationally relevant in the turns in which address terms are used - by invoking the counselling agenda, and by displaying a stronger entitlement to shape the course of the interaction. The first aspect - the use of address terms in not affiliating with the stance of another - is one we might expect to observe in a range of interactional environments; whereas the second may be a particular feature of institutional settings where agendas and entitlements are core to the conduct of these types of encounters.

A common factor across the cases we have examined is that address terms are used where there is a disruption in the contiguity between prior and current talk, action and stance. While in a technical sense, we see in many cases that the turns come in immediately - if not overlapping - adjacent positions, in terms of action and stance, there is clearly a disruption being done. Sequentially (in terms of 'A then B') there is contiguity, but the second position turns (here, the ones with an address term) are not fitted to the prior either with respect to transition relevance, topic and action agendas, or affective stance. An address term, then, serves as some sort of marker of a broken contiguity whether this is observed in relation to sequence organisation, relational organisation, or both. It is through this operation that we see turns with names doing the job of a first pair part in the position of an expected second (Clayman, 2010), or that address terms make a following turn stand out in some way or another. Address terms in turn beginnings work by making salient the independence of the just prior or just subsequent talk from that surrounding it in relation to sequence, and/or in relation to perspective or position. ${ }^{10}$

\footnotetext{
${ }^{10}$ It is important to note, however, that address terms are not always used in turns involving a sequential or interpersonal disjunction - in many instances similar actions are done without the use of an address term. While a quantitative analysis would reveal the proportion of, say, disagreements that involve the use of an address term, that is beyond the scope of this paper. A further caveat worth mentioning is that there appear to be differences between individual counsellors and their use of address terms in that some seem much more likely to use a client's name than others. In addition, come counsellors seem to use address terms in different positions and in different ways, for example, one counsellor seemed to use turn-medial address terms more than other counsellors. These issues of frequency and distribution, and the potential for mapping out the relationships between practice and action, point to the possibility of using conversation analysis to generate statistical information on a situated interactional practice.
} 
We suggest that the environments where address terms are used in turn-beginnings represent a fundamental aspect of the use of personal names that may potentially be observed in a range of environments. However, these practices are used in these examples for context specific purposes the management of telephone counselling. Among these examples, then, the practices or functions of address terms are not merely interactional, but therapeutically oriented.

The environments in which we have described address terms occurring have the potential to be understood as potentially interactionally problematic, in the context of counselling. We have shown address terms used in explicit disagreements and challenges (extract 4), in the context of asking a client to stop talking (extract 3), and in not responding to a client's invited display of understanding (extract 5). Address terms operate in ways that demonstrate or take up a particular stance toward the client, and in many cases this stance is one that is different from that of the client. It is through taking up an opposing stance that the counselling work can be seen to be accomplished, i.e. the counsellor challenges the client's understandings, patterns of behaviour and so on in order to focus on 'change' and the management of a problem. This is accomplished, in many cases, through otherattentiveness, that is, the counsellor focuses on the 'teller' rather than the problem (c.f. Jefferson and Lee, 1992).

In informal discussions with the authors, a Kids Helpline counsellor described their use of clients' names as a way of building and maintaining rapport and trust. Our analysis demonstrates that address terms are tied up with specific interactional practices. Specifically, address terms are used in contexts where the counsellor takes up a stance different from the caller, regularly involving disagreeing with or challenging what the client has said; as well as speaking 'out of sequence' in some way. If names are used to build and maintain rapport and trust (cf. Ivey et al., 2009), then they are used in precisely the moments where that rapport and trust are potentially under threat - i.e. where the counsellor challenges the client's version, starts to speak while the client is still talking, or where delicate actions are being done. Personal names, then, have a double role to play - in highlighting the relevance or importance of what is about to be said, while also mitigating the action that is done with the delivery of these turns (disagreeing, challenging and so on). The institutional asymmetric counsellor-client relationship is made particularly salient through a move that, on the surface, appears to express a certain sort of social solidarity. 


\section{References}

Antaki, C. (2008). Formulations in psychotherapy. In Perakyla, A., Antaki, C., Vehvilainen, S. \& Leuder, I. (Eds.). Conversation Analysis and Psychotherapy. (pp. 26-42). Cambridge: Cambridge University Press.

Antaki, C., Barnes, R. \& Leudar, I. (2005) Diagnostic formulations in psychotherapy', Discourse Studies, 7, 627-47.

Beach, W. A. (1993). Transitional regularities for casual okay usages. Journal of Pragmatics, 19, 325-52.

Bercelli, F., Rossano, F., \& Viaro, M. (2008). Clients' responses to therapists' reinterpretations. In Perakyla, A., Antaki, C., Vehvilainen, S. \& Leuder, I. (Eds.). Conversation Analysis and Psychotherapy. Cambridge: Cambridge University Press.

Brown, R.W. \& Ford, M. (1961). Address in American English. Journal of Abnormal and Social Psychology, 62, 375-385.

Brown, P. \& Levinson, S. C (1987). Politeness: Some universals in language usage. Cambridge: Cambridge University Press

Bolden, G.B. (2009). Implementing incipient actions: The discourse marker 'so' in English conversation. Journal of Pragmatics, 41(5), 974-998

Bolden, G.B. (2006). Little words that matter: Discourse markers "so"' and "oh" and the doing of other-attentiveness in social interaction. Journal of Communication, 56, 661-688.

Butler, C.W., Potter, J., Danby, S., Emmison, M., \& Hepburn, A. (2010). Advice implicative interrogatives: Building 'client centred' support in a children's helpline. Social Psychology Quarterly.

Clayman, S. E. (2010). Address terms in the service of other actions: The case of news interview discourse. Discourse and Communication 4(2): 1-22. 
Danby, S., Baker, C. D., \& Emmison, M. (2005). Four observations on opening calls to Kids Help Line. In C. D. Baker, M. Emmison \& A. Firth (Eds.), Calling for help: Language and social interaction in telephone helplines (pp. 133-151). Amsterdam/Philadelphia John Benjamins.

Danby, S., Butler, C.W. \& Emmison, M. (2009) When 'listeners can’t talk': Comparing active listening in opening sequences of telephone and online counselling. Australian Journal of Communication, 36/3, 91-114.

Danby, S., \& Emmison, M. (in press, June 2011). Kids, counselors and troubles-telling: Morality-inaction in talk on an Australian children's helpline. In J. Cromdal \& M. Tholander (Eds.), Morality in practice: Exploring Childhood, parenthood and schooling in everyday life. London: Equinox.

Emihovich, C.A. (1981). The intimacy of address: Friendship markers in children's social play. Language in Society, 10, 189-199.

Emmison, M., Butler, C.W. \& Danby, S. (2010). Script proposals: A device for empowering clients in counselling. Discourse Studies, 13(1), 1-24.

Emmison, M., \& Danby, S. (2007a). Troubles announcements and reasons for calling: Initial actions in opening sequences in calls to a national children's helpline. Research on Language \& Social Interaction, 40(1), 63-87.

Emmison, M., \& Danby, S. (2007b). Who's the friend in the background? Interactional strategies in determining authenticity in calls to a national children's helpline Australian Review of Applied Linguistics, 30(3), 31.31-31.17.

Fasulo, A. (1997). Other Voices, Other Minds. The Use of Reported Speech in Group Therapy Talk. In L. Resnick, R. Säljö, C. Pontecorvo, \& B. Burge (Eds.), Discourse, tools and reasoning: Essays on situated cognition. NATO Series, Berlin: Springer Verlag, pp. 203-223.

Gardner, R. (2001) When Listeners Talk: Response Tokens and Listener Stance. Amsterdam: Benjamins.

Heritage, J. \& Raymond, G. (forthcoming). Navigating Epistemic Landscapes: Acquiescence, Agency and Resistance in Responses to Polar Questions. In J-P de Ruiter (ed) Questions. Cambridge: Cambridge University Press.

Holt, E. \& Clift, R. (Eds.). (2007). Reporting Talk: Reported Speech in Interaction. Cambridge: Cambridge University Press.

Hutchby, I. (2007) The Discourse of Child Counselling. Amsterdam/Philadelphia: John Benjamins 
Ivey, A.E., Ivey, M.B. \& Zalaquett, Z.P. (2009). Intentional Interviewing and Counseling: Facilitating Client Development in a Multicultural Society. Belmont: Brooks/Cole, Cengage Learning.

Jefferson, G. (1973) A case of precision timing in ordinary conversation: overlapped tag-positioned address terms in closing sequences. Semiotica, 9, 47-96.

Jefferson, G. (1984). Notes on some orderlinesses of overlap onset. In Valentina D’Urso \& Paolo Leonardi (Eds). Discourse Analysis and Natural Rhetorics (pp. 11-38). Padova: CLEUP.

Jefferson, G. (2004). Glossary of transcript symbols with an introduction. In: G. H. Lerner (Ed.), Conversation Analysis: Studies from the First Generation. (pp. 13-31). Amsterdam: John Benjamins.

Lerner, G. H. (2003). Selecting next speaker: The context-sensitive operation of a context-free organization. Language in Society, 32, 177-201.

McCarthy, M. J \& O'Keeffe, A. (2003): 'What's in a name?' Vocatives in casual conversations and radio phone-in calls. In Leistyna, P. \& Meyer, C. (Eds). Corpus Analysis: Language Structure and Language Use. (pp. 153-185). Amsterdam: Rodopi.

Perakyla, A., Antaki, C., Vehvilainen, S. \& Leuder, I. (Eds.). (2008). Conversation Analysis and Psychotherapy. Cambridge: Cambridge University Press.

Rendle-Short, J. (2007). “Catherine, you're wasting your time' : address terms within the Australian political interview. Journal of Pragmatics, 39, 1503-1525.

Rendle-Short, J. (2010). 'Mate' as a term of address in ordinary interaction. Journal of Pragmatics, 42, 1201-1218.

Sacks, H. (1995). Lectures on Conversation (2 Vols.). G. Jefferson (Ed.) Edited by Gail Jefferson with introductions by Emanuel A. Schegloff. Oxford: Basil Blackwell.

Sacks, H., Schegloff, E. A. \& Jefferson, G. (1974). A simplest systematics for the organization of turn-taking in conversation. Language, 50,(4), 696-735.

Schegloff, E.A. (1968). Sequencing in conversational openings. American Anthropologist, 70, 1075-95.

Schegloff, E.A. \& Lerner, G.H. (2009) Beginning to respond: well-prefaced responses to whquestions. Research on Language \& Social Interaction, 42(2), 91 - 115. 
Schegloff, E.A. \& Sacks, H. (1973) Opening up closings. Semiotica, 8, 289-327.

Stivers, T. (2008) Stance, alignment and affiliation during story telling: When nodding is a token of preliminary affiliation. Research on Language in Social Interaction, 41, 29-55.

Vehviläinen, S. (2003). Preparing and delivering interpretations in psychoanalytic interaction. Text, 23, 573-606.

Watson, D. R. (1981). Conversational and organisational uses of proper names: an aspect of counsellor-client interaction. In P. Atkinson \& C. Heath (Eds.), Medical work: Realities and Routines. (pp. 91-106). Farnborough: Gower. 